\title{
Meliponário didático: a extensão universitária como uma estratégia para a conservação das abelhas sem ferrão no semiárido piauiense
}

\author{
Juliana do Nascimento Bendini ${ }^{1}$, Michelli Ferreira dos Santos ${ }^{2}$, Maria Carolina de Abreu' ${ }^{2}$, Gardner de \\ Andrade Arrais ${ }^{2}$, Maria Mayara Vieira ${ }^{2}$, Wllamo Coelho Pacheco Júnior ${ }^{2}$, Vanessa Alves Lima ${ }^{3}$
}

\begin{abstract}
Resumo: Considerando a educação ambiental como instrumento de transformação e uma prioridade entre as ações rumo ao desenvolvimento sustentável, o projeto de extensão universitária "Meliponário didático: uma estratégia para a conservação das abelhas sem ferrão no semiárido piauiense" visa a sensibilização de crianças e jovens, estudantes da educação básica do município de Picos e região, quanto à importância e conservação das abelhas nativas do semiárido piauiense. O presente artigo tem como objetivo relatar as ações e impactos do referido projeto desenvolvido na Universidade Federal do Piauí, em Picos. Para isso, descreveuse o projeto a partir da consolidação do espaço de aprendizagem, desde a formação dos acadêmicos e monitores até a realização das visitas. Os visitantes primeiramente assistem à uma aula, ministrada pelos próprios acadêmicos, sobre as abelhas e seguem para o Meliponário onde observam as abelhas em atividade. Durante as visitas a observação de algumas expressões espontaneamente pronunciadas pelos alunos, nos auxiliam a avaliar os impactos positivos do projeto para a conservação das abelhas nativas, como: "Professora, as abelhas são os cupidos da natureza!" De abril de 2018 a novembro de 2019 foram recebidos 560 visitantes da rede pública de ensino de Picos, de IES e de outros municípios. Considera-se que as ações educativas promovidas no Meliponário Didático da UFPI configuram estratégias eficazes e necessárias para a constituição de uma relação sustentável com as abelhas.
\end{abstract}

Palavras-chave: Caatinga; Educação Ambiental; Meliponicultura; Biodiversidade

\section{Didactic meliponary: University extension as a strategy for the conservation of stingless bees in the Piauí semiarid}

Abstract: Considering Environmental Education as an instrument of transformation and a priority among actions towards sustainable development, the university extension project "Didactic meliponary: a strategy for conservation of stingless bees in the semi-arid region of Piauí" aims to raise the awareness of children and young people, students of primary education in the municipality of Picos and region, regarding the importance and conservation of native bees in the semi-arid region of Piauí. This paper aimed to report the actions and impacts of the referred project developed at the Federal University of Piauí, in Picos, Piauí State, Brazil. The consolidation of the learning space and the training of the monitors to conduct the visits were described. Visitors first attend a class taught by the academics about bees and proceed to the meliponary ("Meliponário") to observe the active bees and their social structure. During the visits, expressions spontaneously pronounced by the students are noted, which helps us to assess the positive impacts of the project for the conservation of native bees. One of the expressions was: "Teacher, bees are nature's cupids!" From April 2018 to November 2019, 560 visitors from public schools in Picos, IES, and other municipalities were received. It is considered that the educational actions promoted at UFPI's Didactic Meliponary are an effective and necessary strategy for the constitution of a sustainable relationship with bees.

Keywords: Caatinga; Environmental Education; Meliponiculture; Biodiversity

\section{Originais recebidos em 06 de junho de 2020}

Aceito para publicação em

01 de setembro de 2020

1

Curso de Licenciatura em

Educação do Campo. Universidade Federal do Piauí (UFPI).

Rua Cícero Duarte, n 905, Bairro Junco, Picos, Piauí, Brasil.

jbendini@ufpi.edu.br

(autora para correspondência)

Curso de Licenciatura em Educação do Campo. Universidade Federal do Piauí (UFPI), Picos, Piauí, Brasil.

3 Curso de Licenciatura em Ciências Biológicas. Universidade Federal do Piauí (UFPI), Picos, Piauí, Brasil. 


\section{Introdução}

Estima-se que há, no mundo, mais de 20 mil espécies de abelhas (Barbosa et al., 2017). No Brasil, as espécies sociais incluem as abelhas domésticas (Apis mellifera L.), introduzidas pelos colonizadores, e as abelhas sem ferrão, pertencentes ao grupo Meliponini, as quais também são chamadas de abelhas nativas ou melíponas. As melíponas são produtoras de mel, cujo consumo é relatado desde o período pré cabralino. O interesse dos produtores rurais e da população em geral por essas espécies foi se intensificando após a regulamentação de sua criação pela Resolução do Conselho Nacional do Meio Ambiente (CONAMA) N 346, de agosto de 2004, e de movimentos de conservação de polinizadores (Villas-Bôas, 2012).

Apesar de não apresentarem produção que possa ser comparada com a da abelha africanizada (Apis mellifera L.), utilizada na apicultura brasileira, as abelhas sem ferrão assumem grande importância na polinização de culturas, bem como da vegetação nativa, já que são responsáveis por até $90 \%$ da polinização das espécies silvestres de ambientes tropicais, não havendo substituto artificial para a polinização capaz de executar de forma tão eficiente o trabalho de uma abelha (Holzschuh et al. 2012). Para Rosso et al. (2003), apesar das abelhas sem ferrão constituírem parte importante da biodiversidade dos agroecossistemas, sua existência ainda passa despercebida pelas pessoas que vivem e trabalham no campo. Além disso, embora extremamente importantes para a manutenção dos ecossistemas, esses insetos estão em processo de desaparecimento, e um dos motivos para tal fato são as ações do ser humano, como desmatamento, queimadas, a ação de 'meleiros' (pessoas que extraem o mel das colônias de forma predatória) e principalmente o uso intenso de pesticidas.

Dessa maneira, muitas espécies correm o risco de desaparecerem antes de serem conhecidas (Brown \& Oliveira, 2014). O enfrentamento dessa problemática envolve a promoção de processos de sensibilização das comunidades rurais acerca da conservação desses insetos.

No Piauí, um dos maiores exportadores de mel proveniente da apicultura (Instituto Brasileiro de Geografia e Estatística [IBGE], 2018), não existem ações sistemáticas de conservação das abelhas, especialmente das nativas, que são culturalmente depreciadas, diante do valor econômico da apicultura.

Estratégias de educação ambiental envolvendo crianças e adolescentes mostram-se excelentes instrumentos para promoção de processos de sensibilização, incluindo seu potencial de atingir indiretamente as famílias, pois ampliam sua percepção sobre temas atuais, como a conservação do meio ambiente e das próprias abelhas (Pereira et al., 2008; Ferreira et al., 2013; Tavares et al., 2016). Segundo Pereira et al. (2008), por apresentarem ferrão atrofiado, o manejo de abelhas nativas não representa riscos de acidentes às crianças e adolescentes, promovendo condições seguras para a observação do funcionamento de uma colmeia, e apropriação de conceitos fundamentais para a compreensão mais geral de sua importância para a conservação da biodiversidade.

Nesse sentido, o projeto de extensão "Meliponário didático: uma estratégia para a conservação de abelhas sem ferrão no semiárido Piauiense", vinculado ao Programa de Extensão "Agroecologia e Educação Ambiental: diálogo entre universidade e escola para a convivência com o Semiárido", objetiva a sensibilização de crianças e jovens, estudantes da educação básica do município de Picos e região, no Piauí, quanto à importância e conservação das abelhas nativas do semiárido piauiense. O projeto considera a Educação Ambiental como um instrumento de transformação e uma prioridade entre as ações rumo ao desenvolvimento sustentável (Bölter \& Nogueira, 2018). 
Dorigo et al. (2020), visando ampliar as discussões acerca das diferentes faces da interação universidade-escola, afirmam que os projetos de extensão são possibilidades eficientes para criação de vínculos e redes de troca entre a comunidade universitária e a sociedade local.

A Extensão Universitária tem sido uma das ferramentas utilizadas para estreitar a relação das universidades com a sociedade (Koglin \& Koglin, 2019) e é umas das práticas acadêmicas capazes de desvendar as possíveis demandas que a sociedade apresenta (Véras \& Souza, 2016). Santana e Silva (2020) chamam a atenção para a necessidade da união entre a teoria e prática em relação ao diálogo e as trocas de saberes e conhecimento.

Dessa maneira, o presente artigo relata as atividades desenvolvidas nos últimos dois anos de execução do projeto de extensão "Meliponário didático: uma estratégia para a conservação das abelhas sem ferrão do semiárido piauiense" na Universidade Federal do Piauí, em Picos.

\section{Procedimentos metodológicos}

Para o cumprimento do objetivo proposto, descreve-se o projeto desde a consolidação do espaço, formação dos acadêmicos e monitores, aquisição das colmeias, convite às escolas para a visitação, e as visitas. Foram utilizados os registros referentes às visitas ao meliponário, desde sua inauguração até o momento.

Outras fontes de dados para este artigo foram: o diário de bordo, e desenhos e histórias produzidos durante uma visita ao meliponário didático realizado por oito alunos do $7^{\circ}$ ano da Unidade Escolar Maria Gil de Medeiros. A visita foi realizada em duas etapas durante as quais foram registrados em um diário de bordo os questionamentos, comentários e as observações realizadas espontaneamente pelos visitantes. Os dados qualitativos apresentados neste artigo são oriundos apenas desta visita.

A primeira etapa da visita consistiu na exposição de informações referentes às abelhas por meio de uma palestra na qual foram apresentados os seguintes temas: as características morfológicas das abelhas, sua diversidade, seu comportamento, sua importância ecológica e as causas do declínio das populações desses insetos (Figura 1A). Na segunda etapa, os alunos foram direcionados ao meliponário (Figura 1B). Os acadêmicos participantes do projeto monitoraram a visita e explicaram sobre a diversidade de espécies de abelhas existentes, bem como suas características e comportamentos. Por fim, os alunos foram incentivados a escreverem histórias e fazer desenhos sobre as abelhas.
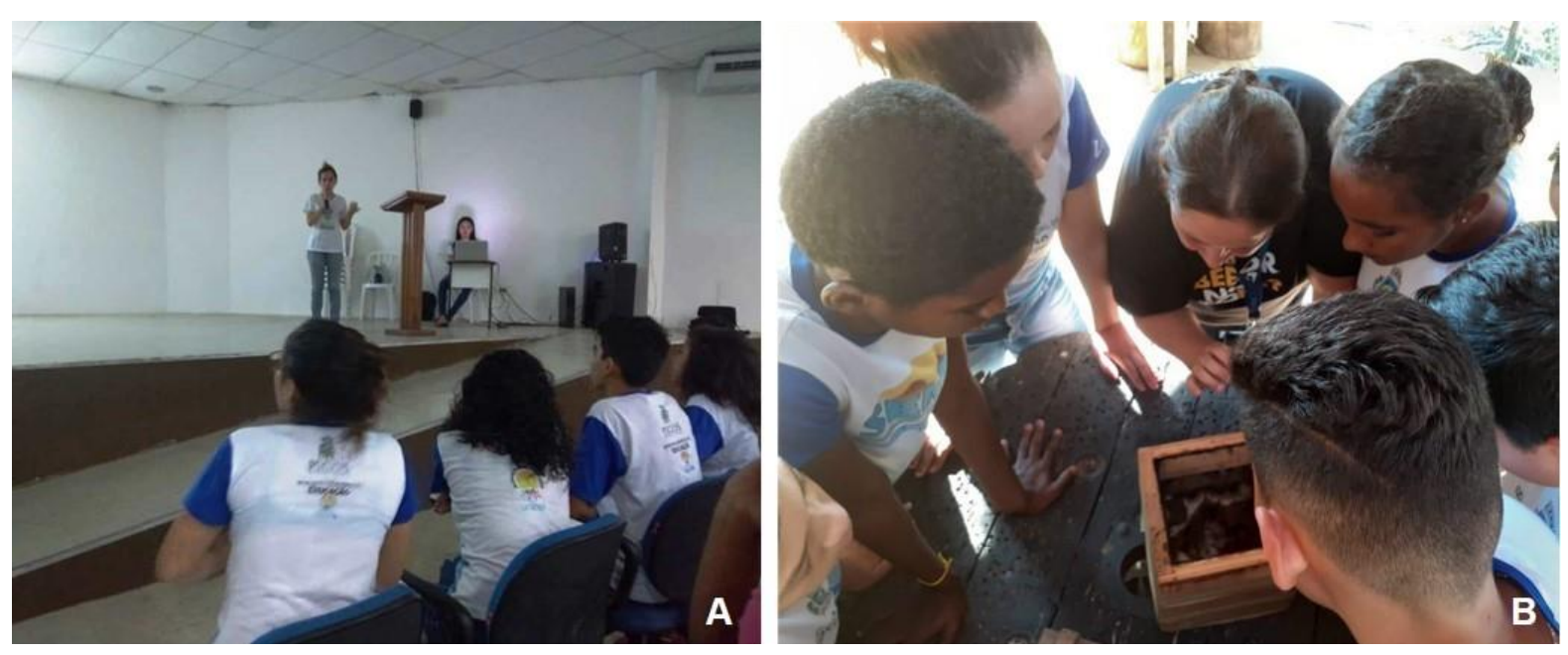
Figura 1. Demonstração da organização social e diversidade de abelhas aos visitantes. A. Palestra no auditório

B. Visita monitorada ao Meliponário Didático.

\section{Localização e instalação do meliponário}

O projeto insere-se na região de Picos, no Estado do Piauí. A mesorregião Sudeste Piauiense, onde localiza-se o município, segundo dados do Instituto Brasileiro de Geografia e Estatística - IBGE, apresenta Índice de Desenvolvimento Humano (IDH) considerado baixo $(0,541)$, podendo assim ser caracterizada como uma região de vulnerabilidade social. A agricultura familiar, e dentro desta, a apicultura, representa, em larga medida, a garantia de renda, especialmente para os povos do campo.

O Meliponário didático foi instalado no Espaço de Convivência com o Ambiente Semiárido (e-CASA), construído em um terreno, antes inativo, cedido pela Universidade em seu campus, lócus das ações do Programa de Extensão da Universidade Federal do Piauí (UFPI) "Agroecologia e Educação Ambiental: diálogos entre a Universidade e Escola para a convivência com o semiárido piauiense".

Neste espaço, as colmeias estão dispostas em uma estrutura de madeira que fica abrigada sob uma palhoça, construída com madeira e palha de carnaúba (Figura 2A). Para a construção da palhoça, iniciada no segundo semestre de 2017, foram doadas madeiras pelo Instituto Brasileiro do Meio Ambiente e Recursos Naturais Renováveis (IBAMA), de Teresina. O restante do material (piso, local para a fixação das colmeias, madeira para a confecção das caixas), bem como a construção da palhoça (inclusive a palha), foi adquirido a partir de recursos próprios. Há também um grande jardim sensorial (que configura outro projeto de extensão do eCASA), no qual são cultivadas espécies meliponícolas em pneus, doados por borracharias locais e pintados pelos membros do projeto. As tintas utilizadas também foram adquiridas com recursos próprios.

\section{Participação dos atores envolvidos para a consolidação do Meliponário}

Os desafios iniciais de construção do espaço para a instalação do meliponário (Figura 2B) até a recepção dos visitantes foram superados por meio do engajamento dos membros do projeto, além das doações de materiais que puderam ser reaproveitados. Além disso, pode-se afirmar que esse engajamento teve como ponto de partida o curso de extensão para a formação de "professores polinizadores", ministrado em julho 2017. A partir desse momento, pode-se afirmar que a sensibilização quanto à importância das abelhas e a preocupação quanto ao risco de seu desaparecimento se tornaram a força motriz para a consolidação do projeto. O "I Curso sobre a importância da formação do professor de Ciências para a preservação dos polinizadores" (conteúdo do curso no Quadro 1) formou 20 acadêmicos dos Cursos de Licenciatura em Educação do Campo e do Curso de Licenciatura em Ciências Biológicas, e quem demonstrou interesse pelo tema passou a participar voluntariamente das atividades do projeto.

Atualmente, o meliponário abriga cinco espécies de abelhas: Jandaíra (Melipona subnitida), Jati (Plebeia sp.), Munduri (Melipona marginata), Mandaçaia (Melipona quadrifasciata) e Abelha Branca (Fresiomelitta sp.), constituindo 8 colônias que se encontram em caixas racionais, modelo Fernando Oliveira (Oliveira \& Kerr, 2000).

Para a consolidação do Meliponário Didático, contamos inicialmente com a participação de apicultores da região semiárida. Um apicultor, por exemplo, sensível à conservação das abelhas nativas, possui em sua propriedade mais de 70 ninhos, alojados em árvores da Caatinga. Sua iniciativa é uma continuação da ação de preservação de árvores e de abelhas, na propriedade, iniciada por seu pai há mais de 40 anos, e resultou na manutenção de uma rica diversidade de espécies de abelhas, que inspirou nosso grupo de estudos à realização de trabalhos científicos sobre as preferências dessas abelhas em relação às plantas da Caatinga, vislumbrando 
a conservação da biodiversidade. Esses diálogos entre a universidade e a comunidade têm incentivado a adoção de práticas voltadas à criação das abelhas nativas entre os produtores, bem como fomentado a articulação entre pesquisa e extensão. Ciente dos objetivos do projeto e empenhado em ações de educação ambiental, o apicultor cedeu ao grupo algumas colmeias de abelhas nativas da Caatinga.

Já com nosso Meliponário didático parcialmente consolidado, foi realizado o curso de extensão "Meliponicultura e Educação Ambiental", em fevereiro de 2018 (conteúdo programático do curso mostrado no Quadro 2). Com duração de $12 \mathrm{~h}$, o curso contou com a participação de acadêmicos dos Cursos de Licenciatura em Educação do Campo e de Licenciatura em Ciências Biológicas.
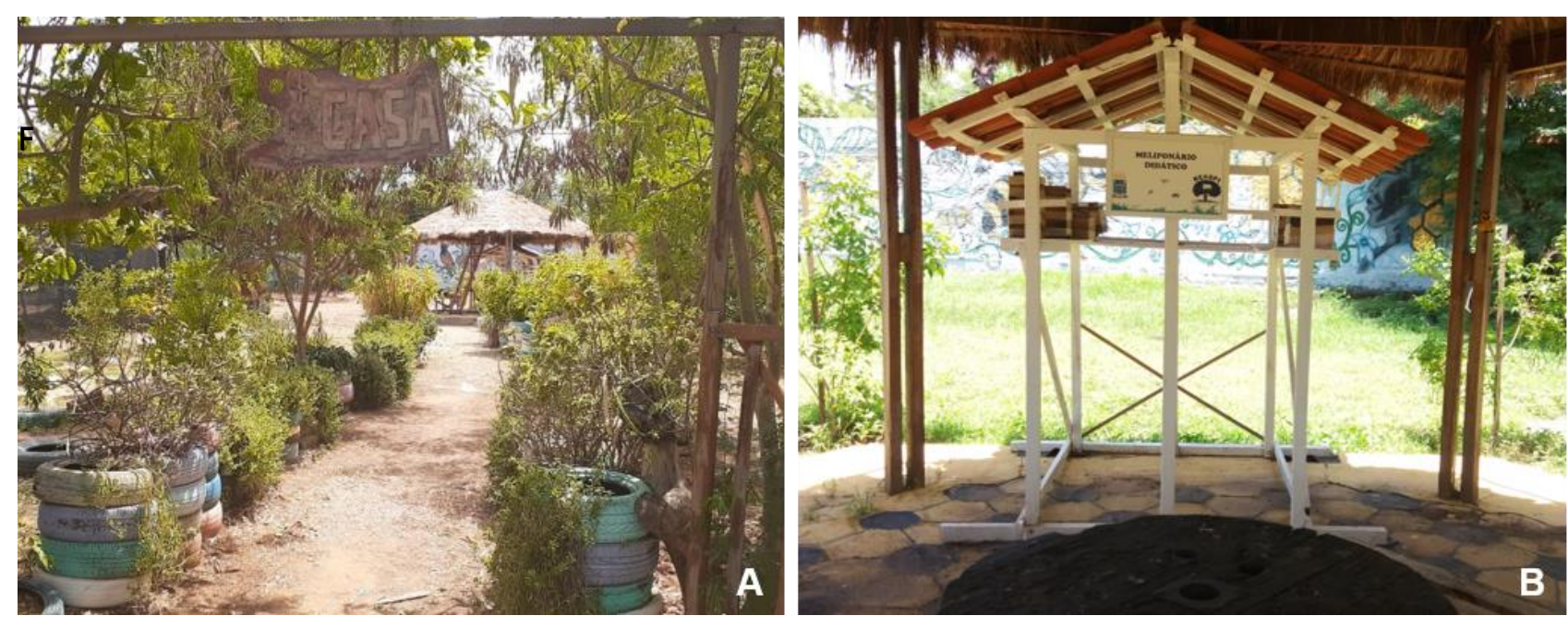

Figura 2. Localização do Meliponário Didático dentro do Espaço de Convivência com o Ambiente Semiárido (e-CASA). A. Localização da palhoça dentro do Espaço. B. Meliponário Didático.

Quadro 1. Conteúdo programático do I Curso sobre a importância da formação do professor de ciências para a preservação dos polinizadores.

\begin{tabular}{|c|}
\hline Unidade 1 - Relação planta-inseto e polinização \\
\hline $\begin{array}{c}\text { Unidade } 2 \text { - A importância das abelhas, causa do desaparecimento das abelhas e declínio dos } \\
\text { polinizadores }\end{array}$ \\
\hline Unidade 3 - Elaboração de projetos didáticos para aplicação em escolas do campo \\
\hline
\end{tabular}

Quadro 2. Conteúdo programático do Curso de Meliponicultura e Educação Ambiental.

Unidade 1 - Caracterização das abelhas, diferenciação das espécies de abelhas sem ferrão e com ferrão

Unidade 2 - Importância ecológica das abelhas 
Unidade 3 - Manejo de colmeias de abelhas sem ferrão/ Prática: Manejo em colmeia de abelhas munduri que compõe o atual Meliponário didático da UFPI

Unidade 4 - Educação ambiental envolvendo a importância das abelhas nativas

Na ocasião, o projeto foi submetido ao Edital do Programa Institucional de Bolsas de Extensão (PIBEX), e contemplado com uma bolsa. As funções executadas pela bolsista estão relacionadas à manutenção das colônias de abelhas sem ferrão, elaboração de palestras e atividades realizadas durante as visitas, e recepção dos visitantes para a demonstração das colmeias. Além da bolsista, atualmente o projeto conta com uma equipe composta por seis alunas e um aluno dos cursos de Licenciatura em Educação do Campo, Licenciatura em Ciências Biológicas, e Nutrição.

As visitas são agendadas previamente pelos diretores e diretoras das Unidades Escolares Municipais de Picos e, por vezes, de outros municípios. Importante destacar que a divulgação é realizada pela equipe participante. Em vários casos, egressos do projeto levam seus alunos do ensino básico para conhecerem o meliponário, revelando que o conhecimento quanto à importância da conservação das abelhas, construído durante a execução do projeto, fomenta uma retroalimentação do processo, que garante a sustentabilidade das ações.

\section{As crianças e as abelhas no e-CASA: resultados de uma visita}

O projeto recebeu até o momento 560 visitantes, crianças e jovens de escolas da região de Picos, além de estudantes da UFPI e do Instituto Federal de Educação, Ciência e Tecnologia do Piaú́ (IFPI) (Quadro 3). No entanto, apresentaremos os resultados qualitativos referentes à visita da turma de oito alunos da Unidade Escolar Maria Gil de Medeiros. Os questionamentos e percepções dos alunos durante a visita ao meliponário didático e as histórias serão tratados como um conjunto único de dados textuais.

Quadro 3. Número de visitas e nomes das Instituições visitantes.

\begin{tabular}{|c|c|c|c|}
\hline VISTIAS & ESCOLA & DATA & $N^{\circ}$ DE ALUNOS \\
\hline $1^{\mathrm{a}}$ & Unidade Escolar Maria Gil de Medeiros & $11 / 04 / 2018$ & 31 \\
\hline $2^{\mathrm{a}}$ & Unidade Escolar Mário Martins & $12 / 04 / 2018$ & 50 \\
\hline $3^{a}$ & Unidade Escolar Francisco José de Araújo & $22 / 05 / 2018$ & 29 \\
\hline $4^{a}$ & Unidade Escolar Araújo Luz & $23 / 05 / 2018$ & 74 \\
\hline $5^{a}$ & Unidade Escolar Joaquim Rodrigues & $11 / 07 / 2018$ & 27 \\
\hline $6^{a}$ & Unidade Escolar Maria Gil de Medeiros & $12 / 09 / 2018$ & 5 \\
\hline $7^{a}$ & Unidade Escolar Maria Gil de Medeiros & $19 / 09 / 2018$ & 16 \\
\hline $8^{a}$ & Universidade Federal do Piauí/Picos & $27 / 09 / 2018$ & 19 \\
\hline $9^{a}$ & Unidade Escolar Miguel Lidiano & $10 / 10 / 2018$ & 6 \\
\hline $10^{\mathrm{a}}$ & Participantes da I Semana da Biologia UFPI & 08/05/2019 & 29 \\
\hline $11^{a}$ & Universidade Federal do Piauí/Picos & 09/05/2019 & 30 \\
\hline $12^{\mathrm{a}}$ & Escola Municipal Francisco José de Araújo & $21 / 05 / 2019$ & 69 \\
\hline $13^{a}$ & Unidade Escolar Araújo Luz & $22 / 05 / 2019$ & 57 \\
\hline $14^{\mathrm{a}}$ & IFPI/Campus Picos & 05/06/2019 & 7 \\
\hline $15^{a}$ & Unidade Escolar Maria Gil de Medeiros & $13 / 09 / 2019$ & 18 \\
\hline $16^{\mathrm{a}}$ & Unidade Escolar Maria Gil de Medeiros & $19 / 09 / 2019$ & 8 \\
\hline
\end{tabular}




\begin{tabular}{|c|c|c|c|}
\hline $17^{\mathrm{a}}$ & Escola Normal Oficial de Picos & $25 / 10 / 2019$ & 28 \\
\hline $18^{\mathrm{a}}$ & Escola Mário Martins & $22 / 11 / 2019$ & 38 \\
\hline $19^{\mathrm{a}}$ & Escola do Município de Ipiranga & $26 / 11 / 2019$ & 19 \\
\hline TOTAL & & 560 \\
\hline
\end{tabular}

Nas histórias e comentários espontâneos, as crianças abordaram uma série de temas, assim categorizados: conservação das abelhas, declínio dos polinizadores, vivências com abelhas, biologia da abelha, polinização e diversidade.

O tema da conservação das abelhas emergiu apenas nas histórias, demonstrado no trecho a seguir:

"Começaram a parar de produzir mel e de polinizar flores e assim os frutos foram diminuindo, até que chegou um dia em que um homem muito preocupado com o que estava acontecendo resolveu ajudar as abelhas, ele montou tipo um "e-CASA" para ela em um lugar cheio de flores e então tudo voltou a ser como era antes." (J. C., 12 anos).

Pôde-se observar, de acordo com a história acima que o aluno descreve uma das causas do declínio das abelhas abordado na palestra (agrotóxicos) e sugere o espaço visitado (e-Casa) como possível solução para conservar as abelhas.

Destacamos que, durante a palestra, os alunos demostraram conhecer algumas causas relacionadas ao declínio dos polinizadores, sendo duas delas, agrotóxicos e queimadas, pertinentes ao que a literatura aponta (Pires et al., 2016). Sobre o desaparecimento das abelhas, seguem os comentários espontâneos dos visitantes:

"Estão desaparecendo por causa do veneno"(M. L., 10 anos).

"Por causa da poluição"(J. H., 11 anos).

"O que causa a morte das abelhas são essas queimadas que acabam matando o mato, pois as abelhas gostam de morar lá" (L. G., 10 anos).

$\mathrm{Na}$ categoria vivências, destacamos as experiências prévias dos alunos com as abelhas. Um dos alunos descreveu uma experiência pessoal sobre um acidente que teve com abelhas. As ferroadas causaram uma reação alérgica que ele descreveu na história:

"Então mãe me levou para casa e ao chegar em casa a mãe falou que o doutor falou que eu era alérgico a abelha. Então, depois disso nunca mais eu quis chegar perto de uma abelha" (M. F., 11 anos).

Sousa e Bendini (2017), investigando a ocorrência de acidentes com abelhas na macrorregião de Picos, Piauí, observaram que, entre os municípios que compõem a referida região, o município picoense é o que mais apresenta notificações de acidentes com abelhas, registrando entre os anos de 2012 e 2015, 219 casos. Segundo os autores, a maioria dos casos ocorre em áreas urbanas, como relatado pelo estudante em sua história.

Observou-se que, apesar de marcante para o aluno, o ocorrido não resultou em nenhum tipo de sentimento de aversão em relação às abelhas, já que o título da história foi "As abelhas não têm culpa". Além disso, o aluno descreve uma moral da história: não mexa com quem está quieto! Foi observado que o aluno não demonstrou medo ou aversão durante a visita ao Meliponário.

A vivência com as abelhas também se faz presente nas menções à atividade apícola e aos produtos da colmeia nos relatos espontâneos dos alunos. Tais referências à apicultura são consideradas naturais, já que esta é uma 
das mais importantes atividades econômicas da região de Picos, e faz parte da realidade de muitas famílias camponesas do semiárido piauiense (Melquíades \& Bendini, 2017).

$$
\begin{aligned}
& \text { "Meu tio tem um negócio de criar as abelhas e eu já fui lá conhecer" (A.L., } 13 \text { anos) } \\
& \text { "Eu conheço um moço apicultor que cria abelhas". (L.G., } 10 \text { anos) } \\
& \text { "Só é ruim quando a gente vai comer o mel e tem ovos". (J.L., } 10 \text { anos) }
\end{aligned}
$$

Outro tema comum nas histórias e nos relatos é a biologia da abelha, do ponto de vista morfológico ou comportamental, o que interpretamos como parte da curiosidade sobre os insetos promovida pelas atividades desenvolvidas durante a visita, como neste extrato:

"Vimos um vídeo explicando quantos olhos as abelhas têm que são cinco e em quantas partes do corpo as abelhas são divididas que é em cabeça, tórax e abdômen. Também vimos quantas antenas tem uma abelha, ela tem duas" (A. L., 12 anos).

As representações descritas pelo aluno se referem às características enfatizadas na palestra por meio da exibição de um vídeo da Campanha Sem abelha, sem alimento. ${ }^{1}$

De acordo com Teixeira e Campos (2005), todas as abelhas sem ferrão (Apidae, Meliponina) são eussociais, ou seja, vivem em colônias cuja população varia de poucas centenas a milhares de indivíduos. As colmeias de abelhas sociais apresentam operárias, zangões e uma rainha que desempenham diferentes funções, todas essenciais para a manutenção da colônia (Nogueira-Neto, 1997).

Como pôde-se observar, os questionamentos, relatos e percepções dos alunos referentes às abelhas, em grande parte, foram relacionados à organização social desses insetos, bem como às características de seus indivíduos, principalmente da rainha, como os exemplos selecionados a seguir:

"A rainha e o zangão são preguiçosos"(M.F., 11 anos).

"A rainha é preguiçosa"(J.C., 12 anos).

"A rainha não morre nesse ambiente fechado?" (J., 10 anos)

"A rainha é maior?" (M.F., 11 anos)

A rainha é biologicamente distinta das operárias, em tamanho e função. Nas visitas, em geral, e com a turma em especial, conseguir enxergar a rainha dentro da colmeia é sempre um momento de grande euforia e expectativa. Como demonstra o trecho da história a seguir, as crianças compreendem a especificidade biológica da rainha, mas isto não pode ser separado das características lúdicas e imaginativas próprias à infância.

"A rainha, como não tinha asas, ela ficava só na colmeia protegendo os ovos, então por isso ela ficava no meio dos ovos" (J. L., 10 anos).

Outro tema identificado nas histórias e nas falas espontâneas dos alunos é a polinização, conteúdo trabalhado também na palestra. Segundo Ricketts et al. (2008), é bastante importante para a produção de alimentos, já que flores que são bem polinizadas fornecem frutos de boa qualidade, peso e sementes em maior quantidade. A polinização, realizada pelas abelhas, foi mencionada em duas histórias e nas falas espontâneas, sempre se referindo à importância desses insetos.

"Começaram a parar de produzir mel e de polinizar flores e assim os frutos foram diminuindo" (J. C., 12 anos). 
"Era uma vez uma abelha em que sua espécie era chamada de Jati. Ela era muito pequena, mas seu tamanho não define o seu trabalho, pois ela podia ser pequena, mas o trabalho era grande. Ela trabalha para rainha polinizando os polens e o néctar"(M.L., 10 anos).

Em uma fala espontânea, um aluno estabeleceu uma interessante metáfora entre a polinização e o papel das abelhas. Ao estabelecer que as abelhas são cupidos, o aluno demonstrou ter compreendido o papel fundamental destes insetos para a polinização e da polinização para conservação da biodiversidade. Esta relação é explorada em diversos momentos da visita ao e-CASA.

"Professora, as abelhas são os cupidos da natureza"(J., 10 anos).

Outro aluno, em comentário espontâneo, fez referência às corbículas.

"A perna de trás que carrega o pólen"(J.L., 10 anos).

Segundo Nogueira-Neto (1997) as operárias, em especial, possuem uma expansão côncava, chamada de corbícula, que é fundamental para transportar pólen. Tal informação foi dada durante a palestra, e assim essa resposta revela o quanto o aluno estava atento ao conteúdo.

Por meio dos comentários, observações e das respostas obtidas, observou-se que os alunos souberam reconhecer uma abelha e que possuíam conhecimento prévio sobre alguns assuntos relacionados a ela, como polinização, produção de mel e comportamento defensivo (ferroadas). Porém, eles não demonstraram conhecimento relacionado à diversidade de espécies. O conteúdo referente à diversidade de abelhas foi abordado em três histórias, sempre em relação às espécies visitadas no meliponário.

"Os amigos do munduri estavam enfeitando a colmeia e os outros jati estavam convidando outras colmeias" (M. L., 10 anos).

"Existem várias outras espécies de abelhas que não podem acabar." (J., 10 anos).

"Era uma vez uma abelha muito pequena que se chamava Jati, ela é a abelha mais pequena do Brasil que também conhece uma outra espécie de abelha com o nome de munduri, que é uma espécie de abelha mais grande diferente da Jati que é minúscula"(J.C., 12 anos)

No Brasil estima-se que existam mais de 2.500 espécies de abelhas, distribuídas em cinco famílias. Dentro das famílias, há muitos gêneros e espécies de abelhas das mais diversificadas formas, cores e tamanhos. Cada espécie apresenta uma característica própria e desempenha um papel particular na natureza (Silva et al., 2014). Embora a estimativa seja de mais de duas mil espécies de abelhas em nosso país, o número de espécies catalogadas é bem inferior. Assim, ações que incrementem o conhecimento de crianças e jovens quanto à diversidade de abelhas existentes no Brasil, ao passo que instiguem a curiosidade deles quanto às suas características, podem consistir em importantes avanços para a conservação desses insetos.

Quanto aos desenhos, observou-se que, embora os estudantes tenham conhecido diferentes espécies de abelhas nativas durante a visita ao meliponário, a forma mais encontrada nos desenhos para a representação das abelhas se refere às abelhas africanizadas Apis mellifera L. utilizadas na produção apícola (Figura 3). Tal observação também foi constatada por Leite et al. (2016).

A avaliação dos desenhos permitiu perceber que, no imaginário dos visitantes, a representação das abelhas se relaciona à espécie Apis mellifera, possivelmente devido ao fato dessa abelha estar sempre representada em desenhos infantis e na maioria das campanhas publicitárias. Além disso, como a região de Picos tem na apicultura uma das atividades econômicas mais importante para os povos do campo (IBGE, 2018), parece natural que essa abelha esteja marcada no imaginário das crianças. 


\section{Considerações finais}

O projeto segue em andamento e, até a conclusão deste artigo, recebeu 560 estudantes. O grande número de visitantes, o interesse e participação dos alunos, verificados através das perguntas e comentários realizados, nos permite concluir que o projeto tem proporcionado a sensibilização do público, contribuindo assim para a conservação das abelhas sem ferrão do Bioma Caatinga.

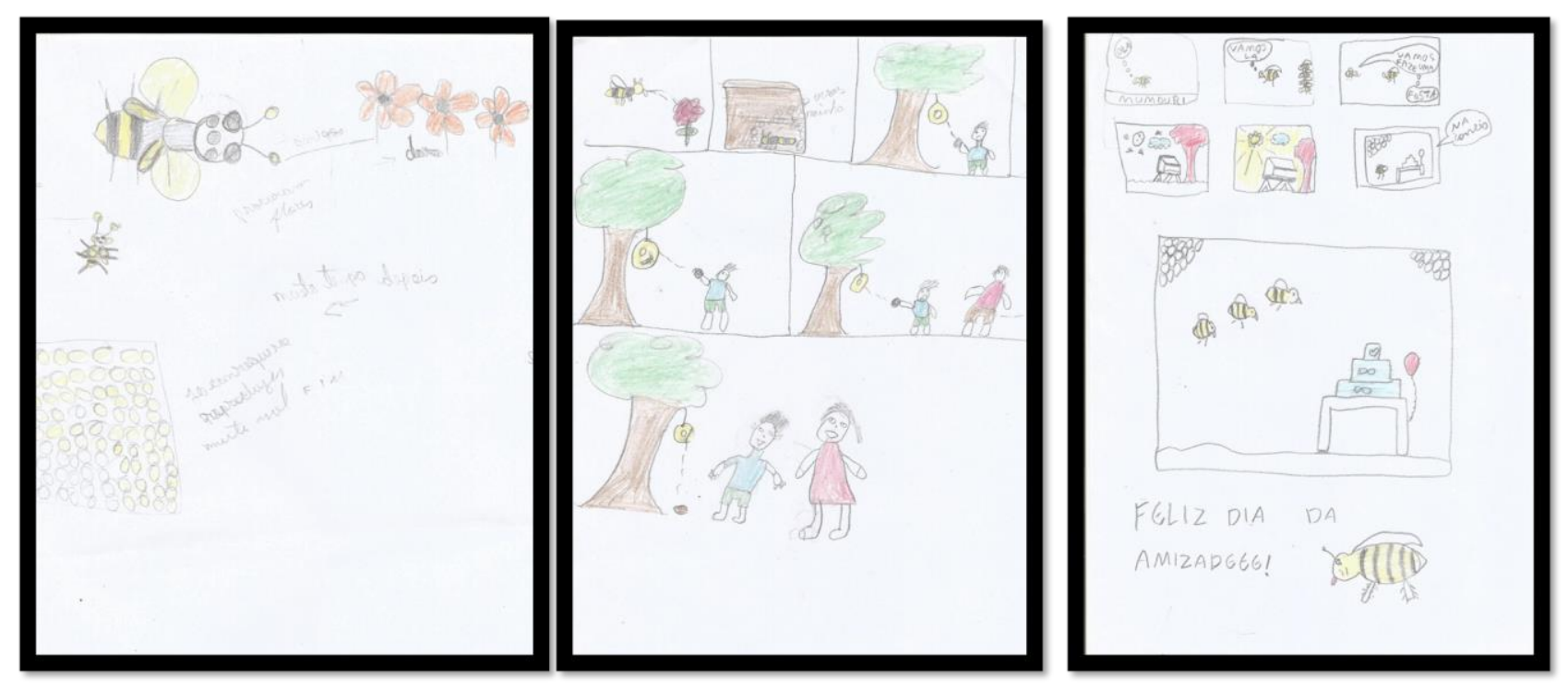

Figura 3. Representações da abelha encontradas nos desenhos dos visitantes.

Dessa maneira, considera-se que as ações educativas consistem em estratégias eficazes e necessárias para o enfrentamento das questões relacionadas ao desaparecimento das abelhas, contribuindo para o aprimoramento das intervenções humanas em prol da conservação da biodiversidade e da melhoria da qualidade de vida dos seres humanos, especialmente das populações mais vulneráveis.

\section{Agradecimentos}

Os autores agradecem ao criador de abelhas Sr. Luiz pela doação de colônias de abelhas, e ao Instituto Brasileiro do Meio Ambiente e dos Recursos Naturais Renováveis - IBAMA, de Teresina, pela doação de madeiras oriundas de apreensão, para a construção do espaço.

\section{Contribuições de cada autor}

J.N.B., M.F.S., M.C.A. e G.A.A. participaram na concepção e planejamento do projeto, na formação dos alunos, construção do Meliponário e na articulação entre a universidade e a escola participante, na execução do projeto, redação e são responsáveis pela aprovação final para publicação. M.M.V., V.A.L. e W.P.C.J. atuaram na manutenção das colônias, nas visitas das escolas ao Meliponário, escrita e revisão do manuscrito.

\section{Nota}

1. Campanha em proteção das abelhas de autoria da Organização não Governamental "Bee or not to be". 


\section{Referências}

Barbosa, D. B., Crupinski, E. F., Silveira, R. N., \& Limberger, D. C. H. (2017). As abelhas e seu serviço ecossistêmico de polinização. Revista Eletrônica Científica da UERGS, 3(4), 694-703.

Bölter, S. G., \& Nogueira, S. V. (2018). Educação ambiental e os desafios para o desenvolvimento sustentável. Ambiente \& Educação, 23(2), 452-465.

Brown, J. C., \& Oliveira, M. L. (2014). The impact of agricultural colonization and deforestation on stingless bee (Apidae: Meliponini) composition and richness in Rondônia, Brazil. Apidologie, 45(2), 172-188.

Dorigo, A. S., Anjos, A., Marcato, A. C. C., Pires-Silva, D., Gonçalves, L. R., Anholeto, L. A., Choalak, L. R., ... \& Cabral-DeMelo, D. (2020). Projeto Primeiros Passos na Ciência: rompendo barreiras sociais e estreitando laços entre a comunidade acadêmica e o Ensino Médio público. Revista Brasileira de Extensão Universitária, 11(1), 47-59.

Ferreira, E. A., Paixão, M. V. S., Koshiyama, A. S., \& Lorenzon, M. C. (2013). Meliponicultura como ferramenta de aprendizado em educação ambiental. Ensino, Saúde e Ambiente, 6(3), 162-174.

Holzschuh, A., Dudenhöffer, J. H., \& Tscharntke, T. (2012). Landscapes with wild bee habitats enhance pollination, fruit set and yield of sweet cherry. Biological Conservation, 1(153), 101-107.

Instituto Brasileiro de Geografia e Estatística. IBGE. (2018). Produção Pecuária Municipal. [S. I.]: IBGE. Recuperado de https:// sidra.ibge.gov.br/pesquisa/ppm/quadros/brasil/2018.

Koglin, T. S. S., \& Koglin, J. C. O. (2019). A importância da extensão nas universidades brasileiras e a transição do reconhecimento ao descaso. Revista Brasileira de Extensão Universitária, 10(2), 71-78.

Leite, R. V. V., Vicente, J. P. C., Oliveira, T. F. F. N., \& Barros, P. K. S. (2016). O despertar para as abelhas: educação ambiental e contexto escolar. In CONEDU-Congresso Nacional de Educação, 3. (pp.1-12). Natal: Editora Realize.

Melquíades, C. C. V., \& Bendini, J. N. (2017). Apicultura no semiárido piauiense: Perspectivas e desafios. In G. A. Arrais, \& J. N. Bendini (Orgs.). Pesquisas e ações do grupo de estudos sobre abelhas do semiárido piauiense. (pp. 35-58). Teresina: EDUFPI.

Nogueira-Neto, P. (1997). Vida e criação de abelhas indígenas sem ferrão. São Paulo: Editora Nogueirapis.

Oliveira, F., \& Kerr, W. E. (2000). Divisão de uma colônia de jupará (Melipona compressipes manaosensis) usando-se uma colmeia e o método de Fernando Oliveira. Manaus: INPA / MCT.

Pereira, C. D., Neto, J. T., Bustamante, N. C. R., Barbosa-Costa, K., Silva, C. G. N., Silva, A. C., ... \& Carvalho-Zilse, G. A. (2008). Curso de meliponicultura, uma reflexão sobre a experiência concreta no ensino e uso sustentável da diversidade de abelhas na Amazônia. Arquivos do Mudi, 12(2/3), 43-49.

Pires, C. S. S., Pereira, F. D. M., Lopes, M. T. D. R., Nocelli, R. C. F., Malaspina, O., Pettis, J. S., \& Teixeira, E. W. (2016). Enfraquecimento e perda de colônias de abelhas no Brasil: Há casos de CCD? Pesquisa Agropecuária Brasileira, 51(5), 422-442.

Ricketts, T. H., Regetz, J., Steffan-Dewenter, I., Cunningham, S. A., Kremen, C., Bogdanski, A., ... \& Viana, B. F. (2008). Landscape effect on crop pollinators services: Are there general patterns? Ecology Letters, 11(5), 499-515.

Rosso, L., Carmona, J. M., \& Garcia, J. (2003). Sensibilizacion en el conocimiento y manejo de abejas nativas por parte de la comunidad campesina Bella Vista (El Dovio, Colombia). Memorias do Seminário Mesoamericano sobre Abejas Sin Aguijon, 3. Tapachula: Chiapas, México. Recuperado de https://www.academia.edu/9324667/ SENSIBILIZACI\%C3\%93N EN EL CONOCIMIENTO Y MANEJO DE ABEJAS NATIVAS POR PARTE DE LA COMUNIDA D CAMPESINA DE BELLAVISTA EL DOVIO COLOMBIA

Santana, C. D., \& Silva, M. R. (2020). A percepção de estudantes da área da saúde sobre o trabalho interdisciplinar: Experiência no projeto de extensão Sorriso de Plantão. Revista Brasileira de Extensão Universitária, 11(1), 13-24.

Silva, C. I., Aleixo, K. O., Nunes-Silva, B., Freitas, B. M., \& Imperatriz-Fonseca, V. L. (2014). Guia ilustrado de abelhas 
polinizadoras no Brasil. São Paulo: Instituto Avançado da Universidade de São Paulo.

Sousa, F. F. \& Bendini, J. N. (2017). Acidentes com abelhas africanizadas na região de Picos, Piauí. 2017. In G. A. Arrais, \& J. N. Bendini (Orgs.). Pesquisas e ações do grupo de estudos sobre abelhas do semiárido piauiense. (pp. 138-169). Teresina: EDUFPI.

Tavares, M. G., Araujo, J. M., Santana, W. C., Elizeu, A. M., Silva, L., A., Ladeira, J. S., ... \& Lino-Neto, J. (2016). Abelhas sem ferrão: Educação para Conservação - Interação Ensino-Pesquisa-Extensão voltada para o Ensino Fundamental. Revista Brasileira de Extensão Universitária, 7(2), 113-120.

Teixeira, L. V., \& Campos, F. N. M. (2005). Início da atividade de vôo em abelhas sem ferrão (Hymenoptera, Apidae): influência do tamanho da abelha e da temperatura ambiente. Revista Brasileira Zoociências, 7(2), 195-202.

Véras, R. M., \& Souza, G. B. (2016). Extensão universitária e atividade curricular em comunidade e em sociedade na Universidade Federal da Bahia. Revista Brasileira de Extensão Universitária, 7(2), 83-90.

Villas-Bôas, J. (2012). Manual Tecnológico: Mel de Abelhas sem Ferrão. Brasília: Instituto Sociedade, População e Natureza (ISPN).

Como citar este artigo:

Bendini, J. N., dos Santos, M. F., de Abreu, M. C., Arrais, G. A., Vieira, M. M., Pacheco Júnior, W. C., \& Lima, V. A. (2020). Meliponário didático: A extensão universitária como uma estratégia para a conservação das abelhas sem ferrão no semiárido piauiense. Revista Brasileira de Extensão Universitária, 11(3), 277-288. https://periodicos.uffs.edu.br/index.php/RBEU/article/view/11554/pdf 